\title{
Article
}

\section{Physical Properties of Modern Reciprocal Endodontic Systems and Fatigue Failure Testing in Simulated Clinical Conditions}

\author{
Alexandr Jusku ${ }^{1}$, Jan Tomáštík ${ }^{2,3}$, Lukáš Václavek ${ }^{2,3}{ }^{\mathbb{D}}$, Petr Jirásek ${ }^{1}$, L'uboš Harvan ${ }^{1}{ }^{\circledR}$, Pavel Holík ${ }^{1}$ \\ and Radim Čtvrtlík ${ }^{2,3, *}$ \\ 1 Institute of Dentistry and Oral Sciences, Medical Faculty, Palacký University in Olomouc, Palackého 700, \\ 77200 Olomouc, Czech Republic; alexandrjusku01@seznam.cz (A.J.); petr.jirasek@upol.cz (P.J.); \\ lubos.harvan@upol.cz (L'.H.); holikpavel@volny.cz (P.H.) \\ 2 Joint Laboratory of Optics of Palacký University and Institute of Physics AS CR, Faculty of Science, Palacký \\ University in Olomouc, 17. listopadu 12, 77146 Olomouc, Czech Republic; jan.tomastik@upol.cz (J.T.); \\ lukas.vaclavek@upol.cz (L.V.) \\ 3 Joint Laboratory of Optics of Palacký University and Institute of Physics AS CR, Institute of Physics of the \\ Czech Academy of Sciences, 17. listopadu 50a, 77207 Olomouc, Czech Republic \\ * Correspondence: radim.ctvrtlik@upol.cz; Tel.: +420-585-631-573; Fax: +420-585-631-531
}

Citation: Jusku, A.; Tomáštík, J.;

Václavek, L.; Jirásek, P.; Harvan, L'.; Holík, P.; Čtvrtlík, R. Physical Properties of Modern Reciprocal Endodontic Systems and Fatigue Failure Testing in Simulated Clinical Conditions. Appl. Sci. 2021, 11, 11160. https://doi.org/10.3390/app112311160

Academic Editor: Gabriele Cervino

Received: 20 October 2021

Accepted: 19 November 2021

Published: 24 November 2021

Publisher's Note: MDPI stays neutral with regard to jurisdictional claims in published maps and institutional affiliations.

Copyright: (c) 2021 by the authors. Licensee MDPI, Basel, Switzerland. This article is an open access article distributed under the terms and conditions of the Creative Commons Attribution (CC BY) license (https:/ / creativecommons.org/licenses/by/ $4.0 /)$.

\begin{abstract}
Instrument fracture ranks among the most crucial complications during the endodontic treatment of a tooth. In order to better understand the practical limits of the instrument, the relation between the cyclic fatigue resistance and physical properties such as hardness, modulus of elasticity, creep and surface roughness were explored. Cyclic fatigue testing in an artificial root canal at intracanal temperature, nanoindentation and 3D microscopy were used for evaluation of four commonly used thermomechanically treated NiTi endodontic instruments (Unicone Plus 6/025, Unicone 6/025, Reciproc Blue R25 and WaveOne Gold Primary). Cyclic fatigue results were analyzed using the Kruskal-Wallis, Mann-Whitney and Bonferroni corrections. The wear resistance of Unicone 6/025 instruments was significantly lower compared to all other instruments $(p<0.05)$. WaveOne Gold Primary was significantly less resistant than Unicone Plus 6/025 and Reciproc Blue R25, while the difference between Reciproc Blue R25 and Unicone Plus 6/025 was insignificant ( $p>0.05$ ). These results are in correlation with measurements of local mechanical properties (hardness, elastic modulus and their ratios $H / E$ and $H^{3} / E^{2}$ ). Even though surface roughness, area of cross-section and shape of instruments are important factors affecting instruments behavior, thermal processing appears to be the most important.
\end{abstract}

Keywords: cyclic fatigue; endodontic instruments; nanoindentation; roughness

\section{Introduction}

One of the complications during endodontic treatment is instrument fracture during the shaping phase [1]. This often results in tooth extraction and leads to lowering the quality of oral health. Fracture of endodontic instrument is caused by exceeding either the limit of cyclic fatigue resistance or the torque fatigue resistance [2-7]. It is the cyclic fatigue resistance that is especially considered one of the most important parameters, and its testing is of the highest importance.

Today the instruments made of nickel-titanium alloys, introduced to endodontics by McSpadden in 1992 [8], widely complement the traditional steel instruments. Among these alloys, a special rank belongs to nitinol, with a near-equiatomic composition (56 wt.\% of $\mathrm{Ni}$ and $44 \mathrm{wt} \%$ of $\mathrm{Ti}$ ) and structure combining two possible phase modifications of NiTi with different properties: austenite and martensite. Austenite is a high temperature phase (cubic B2 crystal structure) responsible for high stiffness, hardness and superelastic properties; on the contrary, martensite is a low temperature phase (monoclonic B19' crystal structure) with lower elastic modulus that brings ductility and shape memory effect to 
the alloy [9]. The internal structure of nitinol instruments can reversibly switch from one to another without any visual changes in the instrument. This phase switching, called the martensitic transformation, can be induced by stress and/or by changing the ambient temperature [10]. It was also found that specific heat treatment procedures can lead to creation of a rhombohedrally distorted phase (R-phase) [11] exhibiting even lower elastic modulus than a martensite phase [12].

Due to the possible existence/co-existence of different crystallographic phases, the mechanical and fatigue properties of nitinol instruments strongly depend on a particular phase composition [9] predetermined by the thermal treatment during manufacturing. Alloy phase and chemical composition together with surface roughness, shape, and crosssectional area [13] are generally noted as intrinsic parameters with a crucial impact on overall instrument performance [14-22]. Additionally, there are multiple ambient factors governing the cyclic fatigue of endodontic instruments, such as type of motion (continuous, various reciprocating), ambient temperature, and artificial root canal geometry [13]. In general, cyclic fatigue tests of endodontic instruments are not completely standardized. Nowadays, cyclic fatigue tests are performed mainly using an artificial canal, usually grooved in a stainless steel block $[14,20,23]$. Canal curvature is usually between $30^{\circ}$ and $90^{\circ}$ with a variable curvature radius $[14,16,24,25]$.

Former studies of fatigue resistance and torque fatigue resistance were accomplished either mainly at room temperature [26-28] or at body temperature, $37^{\circ} \mathrm{C}[16,23]$, even though a temperature inside the root canal system of $35^{\circ} \mathrm{C}$ is reported $[14,29]$. There are several studies showing that higher ambient temperature reduces cyclic fatigue resistance [14,30-32] by affecting the internal crystallographic structure (switching martensite to austenite ratio), which leads to lowering the cyclic fatigue resistance in intracanal temperature compared to room temperature $[33,34]$. On the contrary, there are a few studies claiming that switching ambient temperature from room to body temperature does not affect cyclic fatigue resistance [23,35]. This ambiguity and inconsistency in results stems from using different experimental setups (artificial canals with variable curvature angles made from ceramics and stainless steel) under different environmental conditions [23]. Taking into the account the in vivo physiological conditions and the applicability of previously obtained results, the only relevant cyclic fatigue studies are those performed at $35^{\circ} \mathrm{C}$. Therefore, the testing temperature of $35^{\circ} \mathrm{C}$ was used in this study, as it has the highest information content and greatest relevance for clinicians.

Despite the controversy accompanying the fatigue testing of endodontic instruments on account of contradictory information and its multi-variable nature [36], there is a tremendous need for a better understanding of the durability of nitinol-based instruments. In particular, data obtained at clinical conditions or at simulated close-to-clinical conditions considering specific parameters or variables are of the highest importance [37]. The purpose of this study is to further explore and elucidate the relationships between cross-sectional area and surface roughness, as well as appropriate mechanical properties including hardness, creep and elastic modulus, in connection with the cyclic fatigue resistance of commonly used endodontic instruments in order to provide new insight into their mechanical durability. The tested instruments include files made by similar working procedures, WaveOne Gold, Reciproc Blue, and Unicone Plus, and one instrument made from M-wire, called Unicone, which is made from a differently-treated NiTi alloy.

\section{Materials and Methods}

\subsection{Materials}

Three commonly used endodontic instruments belonging to the class of reciprocating instruments Unicone 6/025 (Medin, Nové Město na Moravě, Czech Republic), Reciproc Blue R25 (VDW, Munich, Germany) and WaveOne Gold Primary (Dentsply Sirona, York, PA, USA) were thoroughly compared with the recently introduced endodontic instrument Unicone Plus 6/025 (Medin, Nové Město na Moravě, Czech Republic). All tested instruments possessed the same tip diameter $(0.25 \mathrm{~mm})$ and length $(25 \mathrm{~mm})$. However, they 
differed in taper (conus), cross-section profile and manufacturing process. Unicone 6/025 and Unicone Plus 6/025 have a constant $6^{\circ}$ taper. Reciproc Blue has a variable taper starting at $8^{\circ}$ in the first few millimetres from the tip and decreasing to $4^{\circ}$ closer to the shaft. WaveOne Gold has variable conus starting at $7^{\circ}$ in the first few millimetres from the tip and decreasing to $3^{\circ}$ closer to the shaft. It should be noted that Unicone Plus, Reciproc Blue and WaveOne Gold all underwent appropriate heat treatment during the manufacturing process.

\subsection{Cyclic Fatigue}

Ten instruments of each type were subjected to a cyclic fatigue test in 5\% sodium hypochlorite water-based solution at a temperature of $(35 \pm 1)^{\circ} \mathrm{C}$. A total of 40 instruments were used for the study, which were inspected with a stereomicroscope at $20 \times$ magnification before testing in order to exclude any damaged instruments. Since there is no standardized test for cyclic fatigue in endodontics, a special device was designed and constructed, similar to previous studies [14,23]. The model of the artificial root canal was made of stainless steel, with a $7 \mathrm{~mm}$ radius of curvature, $0.5 \mathrm{~mm}$ diameter in the instrument tip area, conicity of 0.07 starting $1 \mathrm{~mm}$ from the instrument tip area, $70^{\circ}$ curvature angle, and the center of the curve at $5.8 \mathrm{~mm}$ from the instrument tip area was manufactured to simulate the physiological geometry of the root canal. This artificial root canal was immersed into the thermostatic bath. The temperature was maintained throughout the test and checked with an infrared thermometer (see Figure 1).

a)

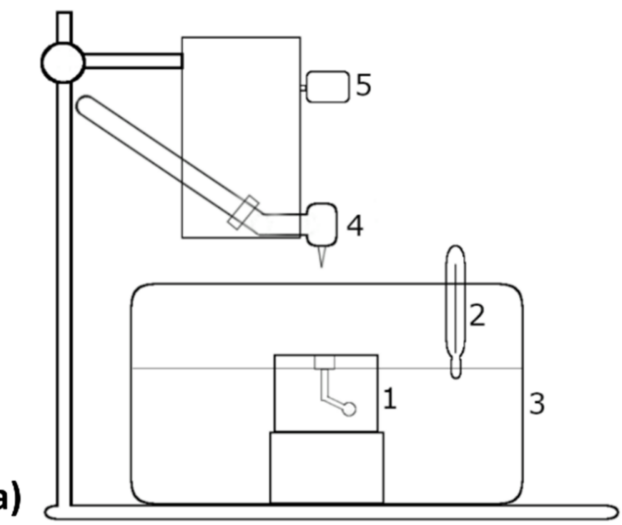

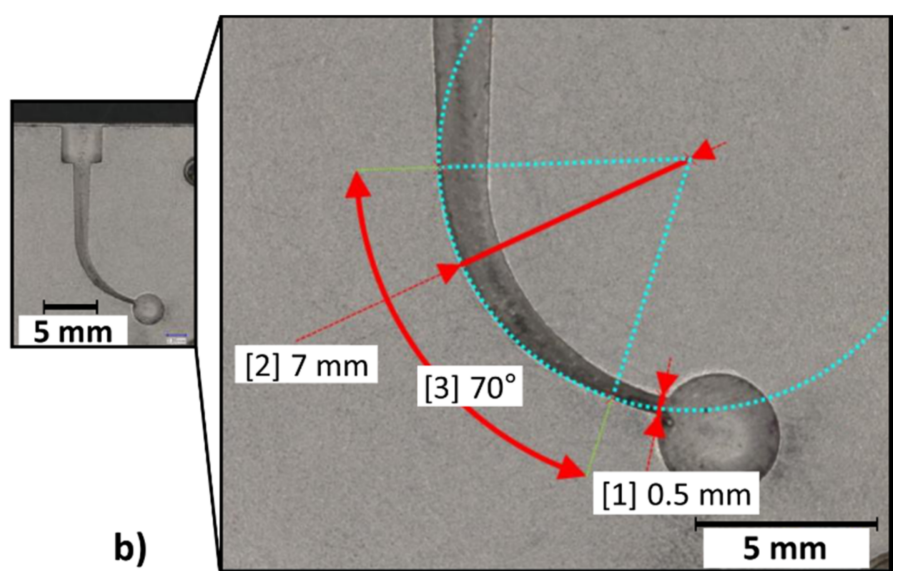

Figure 1. Experimental setup for cyclic fatigue testing (a) overall design: 1. Artificial root canal, 2. Infrared thermometer, 3. Thermostatic bath, 4. Handpiece with endodontic instrument, 5. Mobile device for precise insertion of the instrument and (b) detail of the artificial root canal: 1. Diameter in the area of tool tip, 2. Radius of curvature, 3. Angle of curvature.

All instruments were tested using a 6:1 speed reducing handpiece (VDW, Munich, Germany) powered by a WaveOne endomotor (Dentsply Maillefer, Ballaigues, Switzerland). The handpiece was fixed on a mobile device suitable for precise insertion of an instrument into the canal. Instruments were tested in "Reciproc ALL mode". To evaluate the cyclic fatigue of the instruments, time was measured until fracture occurred, with an accuracy of whole seconds. Since the obtained results did not meet the assumptions of a normal distribution (Shapiro-Wilk Test), the non-parametric Kruskal-Wallis test was used for statistical evaluation, followed by post hoc tests (Mann-Whitney U-tests of multiple comparison with Bonferroni corrections), all at a significance level of $5 \%$.

\subsection{Local Mechanical Properties}

Hardness, reduced elastic modulus and creep of NiTi instruments were measured with a fully calibrated NanoTest instrument (Micro Materials, Wrexham, UK). Standard loadcontrolled nanoindentation tests were performed with a three-sided diamond Berkovich indenter at a normal force of $50 \mathrm{mN}$ in order to assess hardness and elastic modulus values. 
In addition, nanoindentation creep experiments were performed at a load of $200 \mathrm{mN}$ to explore the rheological response of the instruments. The indenter was calibrated using a standard fused silica reference sample. The nanoindentation took place with a time course of $10 \mathrm{~s}$ loading and $10 \mathrm{~s}$ unloading; a dwell period of $10 \mathrm{~s}$ was used for the standard test and $120 \mathrm{~s}$ for the creep test.

Nanoindentation tests were performed on transversal cross-sections. Vertically oriented NiTi instruments were fixed in the epoxy resin Dentacryl (Spofadental, Jičín, Czech Republic) and machined through grinding and fine polishing. Two transversal crosssections were prepared in two steps, first $2 \mathrm{~mm}$ and then $6.4 \mathrm{~mm}$ from the apex of the instrument. The distance of $2 \mathrm{~mm}$ from the apex was chosen so that there was a sufficient area for indentation measurements, and the distance of $6.4 \mathrm{~mm}$ was chosen as it corresponds to a typical location of a fracture of instruments (the break point of the test tips) during cyclic fatigue tests. The indentation matrix of $4 \times 5$ indents was located in the central part of both cross-sections, while spacing between indents was $30 \mu \mathrm{m}$. The nanoindentation curves were evaluated by the standard Oliver-Pharr method [38] for determination of hardness and reduced elastic modulus values. Indentation measurements were performed on three instruments for each manufacturer. Creep measurements were done on one arbitrarily chosen instrument for each manufacturer.

Microscopic observation of the instrument cross-sections and surfaces was carried out using a laser scanning confocal microscope (OLS LEXT 5000, Olympus, Tokyo, Japan) at different magnifications. Dimensional analyses in both 2D and 3D were used both for measuring the area of cross-sections and for non-contact roughness measurement. The latter was measured on the side (outer) wall of the endodontic files. Linear roughness was obtained from ten lines drawn in the field of view acquired using $\times 100$ objective. A low pass filter (cut-off) of $\lambda_{c}=100 \mu \mathrm{m}$ had to be used to remove surface waviness from the roughness data.

\section{Results}

The results of the cyclic fatigue test, represented by the time of operation until fracture, are summarized in Table 1. Reciproc Blue, Unicone Plus and WaveOne Gold instruments exhibited statistically significantly higher cyclic fatigue resistance than Unicone $(p<0.05)$. Reciproc Blue and Unicone Plus showed statistically significant higher cyclic fatigue resistance than WaveOne Gold $(p<0.05)$. Although Unicone Plus showed lower cyclic fatigue resistance than Reciproc Blue, the difference was not statistically significant $(p>0.05)$. For clarity a cumulative frequency plot is shown in Figure 2, representing the percentage of fractures of each instrument at certain times. One can see that all Unicone instruments had failed already before the first instrument in the other groups. All fractures took place over a range of distances from $5.0 \mathrm{~mm}$ to $6.3 \mathrm{~mm}$ from the apex, with no statistical differences among the instruments.

Table 1. Mean of time to fracture of tested samples.

\begin{tabular}{lcccc}
\hline & WaveOne Gold & Reciproc Blue & Unicone Plus & Unicone \\
\hline Time to fracture $(\mathrm{s})$ & $214.6 \pm 20.7$ & $262.9 \pm 35.5$ & $245.1 \pm 32.1$ & $78.6 \pm 11.9$ \\
Fracture position $(\mathrm{mm})$ & $5.5 \pm 0.4$ & $5.7 \pm 0.5$ & $5.8 \pm 0.5$ & $5.4 \pm 0.4$ \\
\hline
\end{tabular}




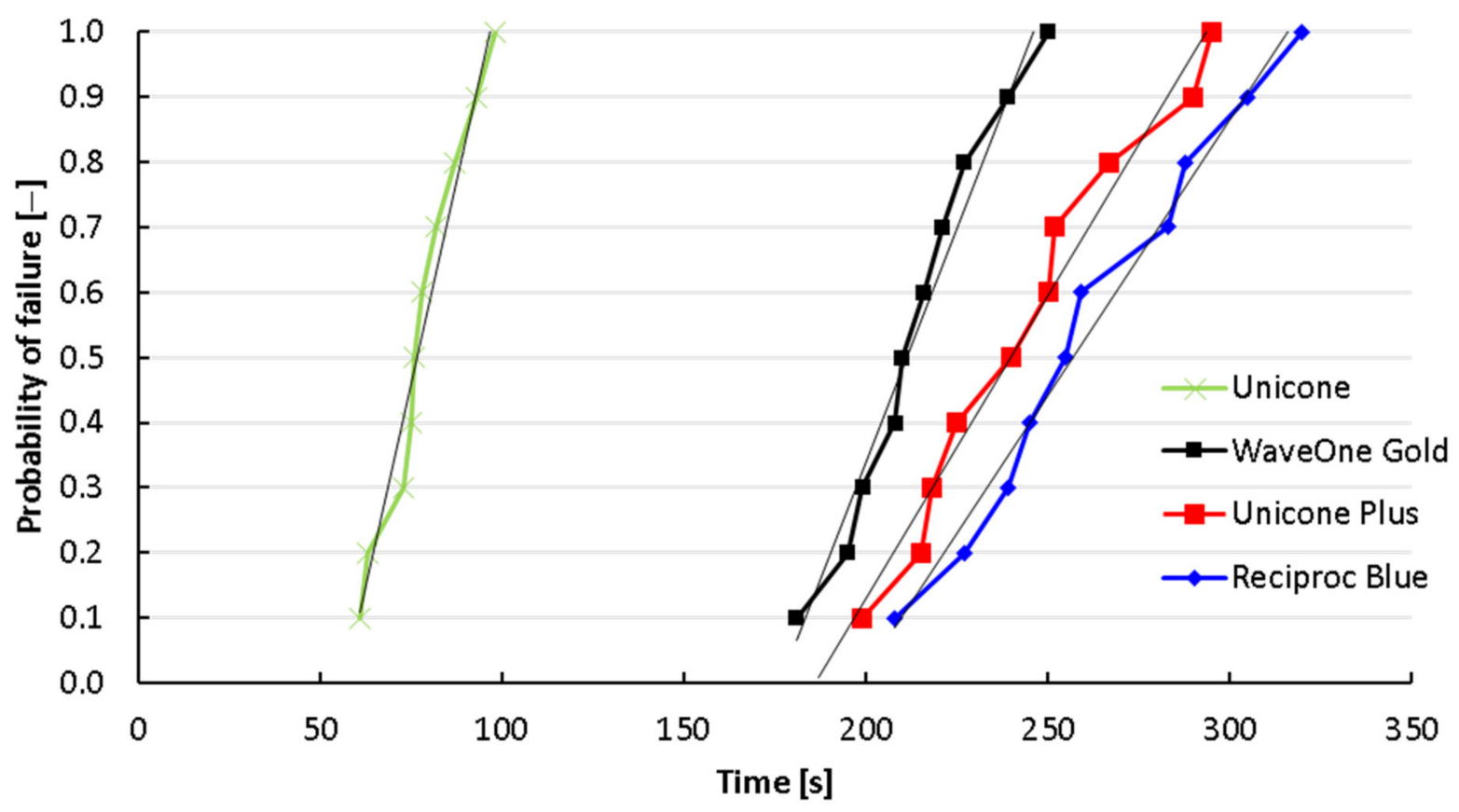

Figure 2. Probability of fracture vs. time to failure sets of ten samples for each evaluated instrument.

The comparison of the transversal cross-section of the instruments reveals their completely different design, as can be seen in Figure 3, showing polished cross-sections at a distance of $6.4 \mathrm{~mm}$ from the apex. Both WaveOne Gold and Unicone exhibit the smallest cross-sectional areas, as summarized in Figure 4, for $2.0 \mathrm{~mm}$ and $6.4 \mathrm{~mm}$ distances from the apex. The ratio of the cross-sectional areas between the two distances of the different tools differs due to their variable conicity.

Line roughness was measured using a non-contact procedure on the side of the file. The defined areas are shown in real colours in Figure 5, including the representative surface profiles (out of ten) which were used for roughness calculation. Three samples were measured for each type of endodontic file; the calculated data are summarized in Table 2. It can be seen that Unicone Plus exhibits the lowest values by far in all observed roughness parameters. Unicone and Reciproc Blue files exhibit intermediate roughness values, while the WaveOne Gold shows the highest values for the most used parameters in practice, $\mathrm{Ra}$ and $\mathrm{Rq}$ (Rms). Besides Ra and Rq (also called RMS), other topographical measures are shown in Table 2, where Rz is the maximum height of profile, Rc is the mean height of profile elements and Rt stands for the total height of profile [39].

Table 2. Roughness parameters on the side wall of the endodontic files.

\begin{tabular}{cccccc}
\hline & $\mathbf{R a}[\boldsymbol{\mu m}]$ & $\mathbf{R q}[\boldsymbol{\mu m}]$ & $\mathbf{R z}[\boldsymbol{\mu m}]$ & $\mathbf{R c}[\boldsymbol{\mu m}]$ & $\mathbf{R t}[\boldsymbol{\mu m}]$ \\
\hline Unicone & $0.29 \pm 0.08$ & $0.39 \pm 0.12$ & $2.22 \pm 0.64$ & $1.28 \pm 0.35$ & $3.47 \pm 1.54$ \\
WaveOne gold & $0.54 \pm 0.05$ & $0.67 \pm 0.06$ & $3.34 \pm 0.30$ & $2.01 \pm 0.27$ & $4.16 \pm 0.55$ \\
Unicone Plus & $0.19 \pm 0.03$ & $0.26 \pm 0.05$ & $1.63 \pm 0.36$ & $0.78 \pm 0.20$ & $2.46 \pm 0.62$ \\
Reciproc Blue & $0.36 \pm 0.10$ & $0.45 \pm 0.13$ & $2.62 \pm 0.80$ & $1.56 \pm 0.49$ & $3.41 \pm 0.95$ \\
\hline
\end{tabular}




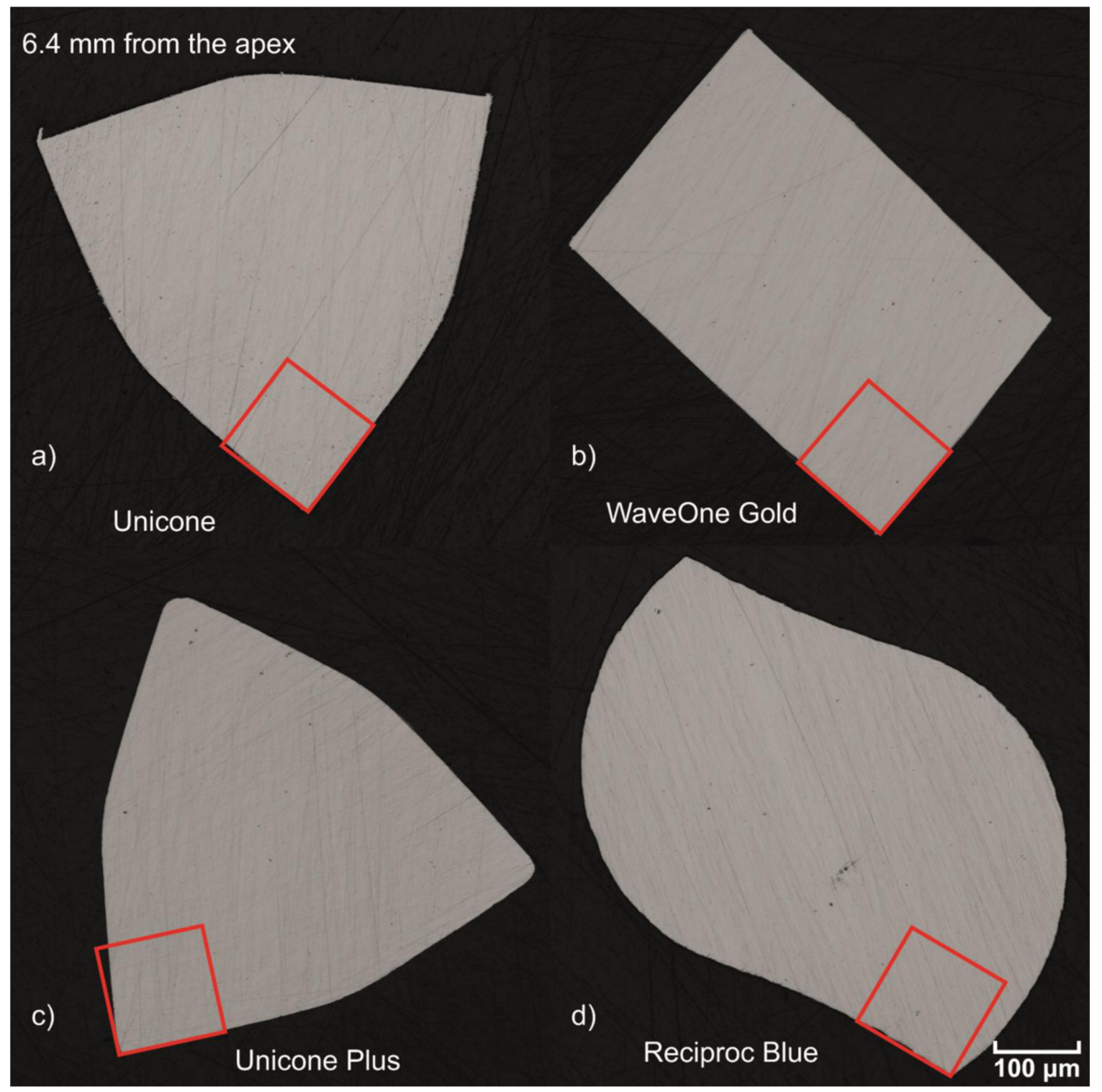

Figure 3. Microscopic image of the cross-sections at a distance of $6.4 \mathrm{~mm}$ from the apex of the instruments (a) Unicone, (b) WaveOne Gold, (c) Unicone Plus, (d) Reciproc Blue. Red squares are used for better comparison of the shape of the instruments.
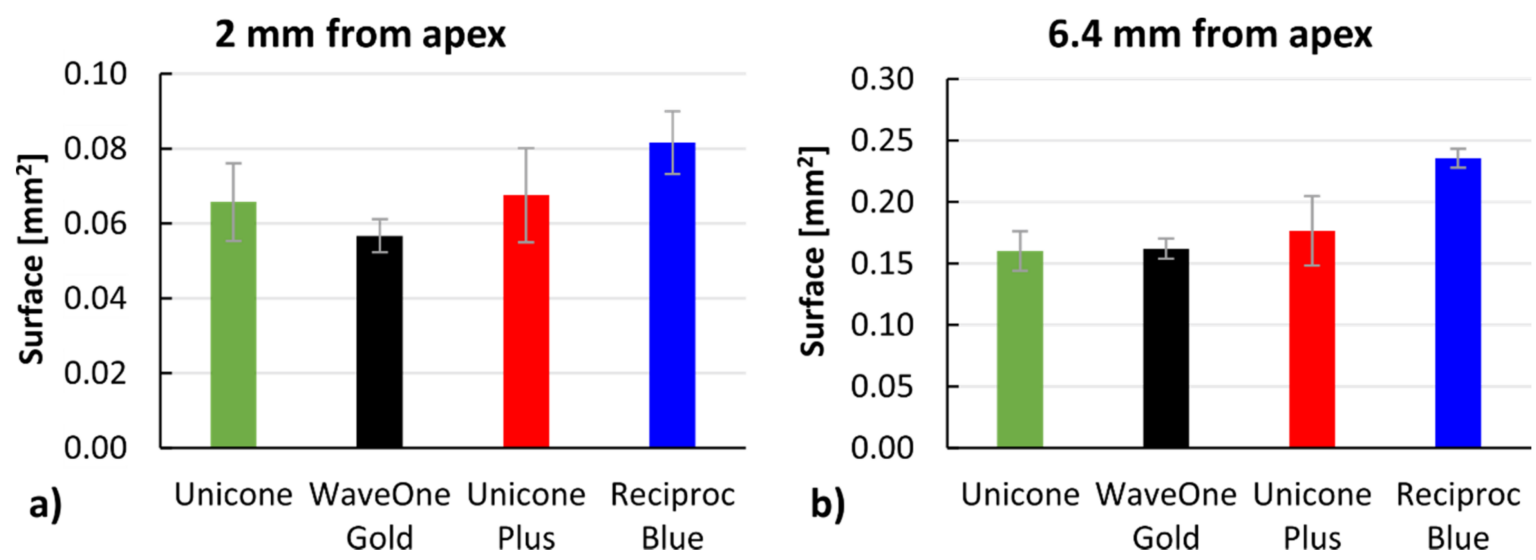

Figure 4. Surface area measured on two transversal-cross section positions at a distance of (a) $2 \mathrm{~mm}$ and (b) $6.4 \mathrm{~mm}$ from the apex of the instruments. 

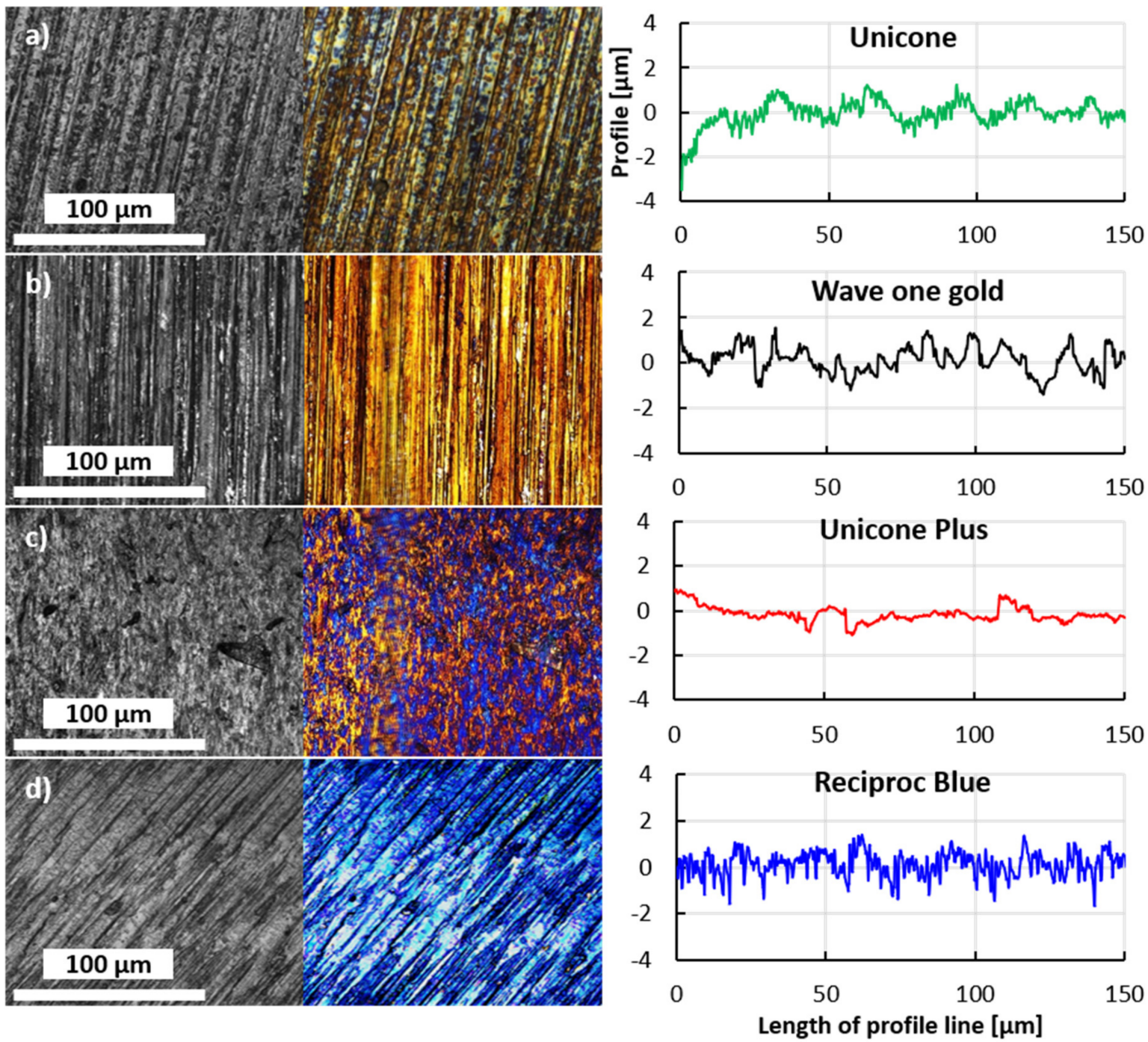

Figure 5. Micrographs of the side walls of the instruments, intensity (left) and color (right) representation, with chosen roughness profile: (a) Unicone, (b) WaveOne Gold, (c) Unicone Plus and (d) Reciproc blue.

The results summarized in Figure 6 show that Unicone has significantly higher hardness (approximately $4 \mathrm{GPa}$ ) than other three instruments (approximately $3 \mathrm{GPa}$ ), which show very similar hardness. It should be noted that $4 \mathrm{GPa}$ is a typical value for a commercial austenitic NiTi superelastic alloy. Unicone Plus and Reciproc Blue exhibit a very small but observable decrease of hardness between cross-sections (2 and $6.4 \mathrm{~mm}$ from the apex), which is not observable for WaveOne Gold and Unicone.

Time-dependent plastic deformation, known as creep, was evaluated using a time period of $120 \mathrm{~s}$. Sets of normalized creep curves for all three instruments are presented in Figure 6 for comparison. The normalization was performed by subtracting the initial creep depth measured at the beginning of the dwell period, when the normal force was kept constant. Despite the natural spread of creep curves, Figure 7 provides a qualitative comparison of the tendency of the material to deform under constant indentation load. Comparing the penetration depth, one can see significantly lower tendency to creep for Unicone in comparison to other three samples. Minor differences are also observable between other samples, where WaveOne Gold shows a lower tendency to creep than Unicone Plus and Reciproc Blue. 

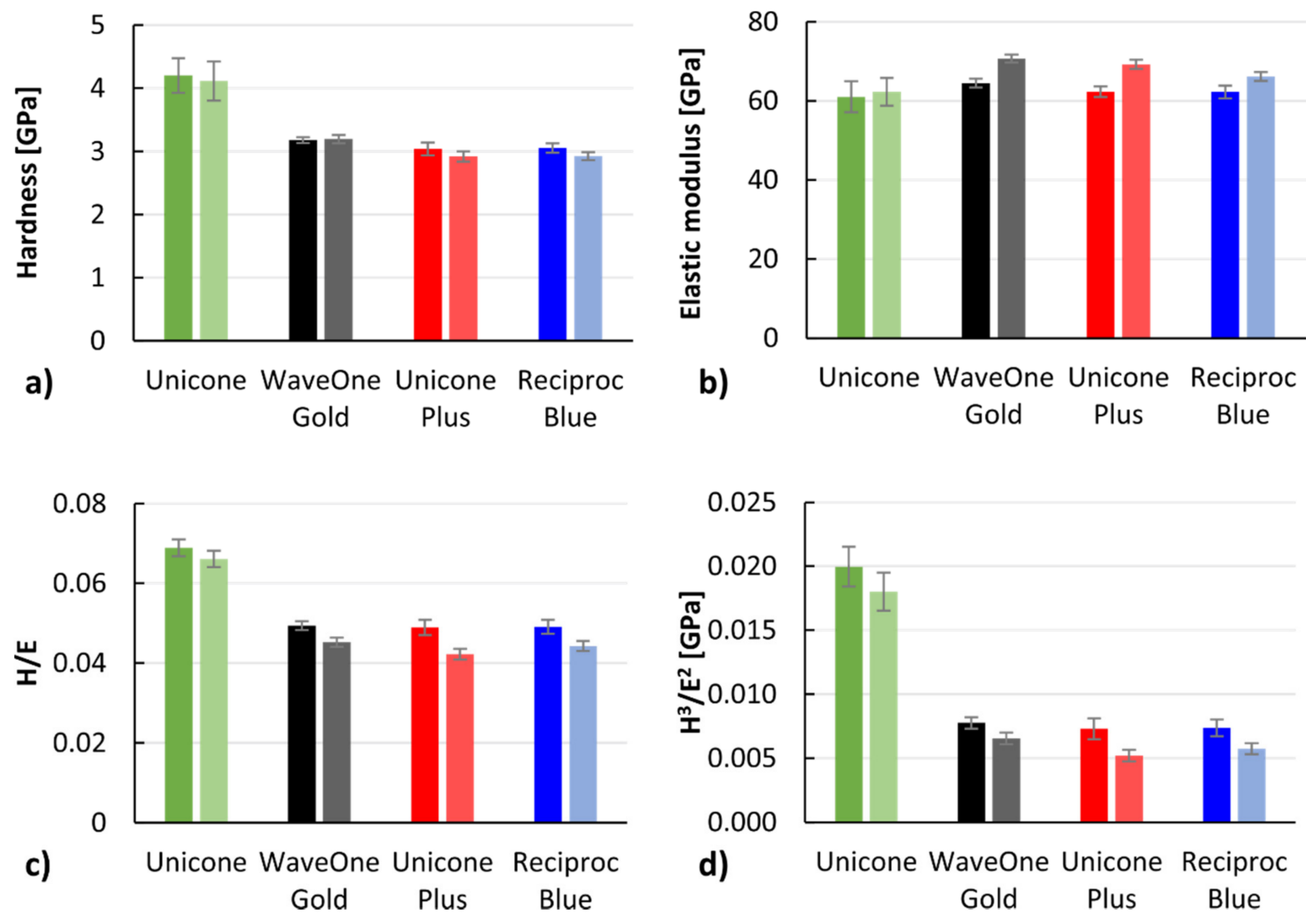

Figure 6. Results of the nanoindentation test performed with a Berkovich indenter at two distances from the apex of the instruments. Values of (a) hardness $H,(\mathbf{b})$ reduced elastic modulus $E$ and ratios of (c) $H / E$ and (d) $H^{3} / E^{2}$ for tested instruments. Dark bars represent test done at the distance of $2 \mathrm{~mm}$ and light bars represent test at the distance of $6.4 \mathrm{~mm}$ from the apex of the instrument.

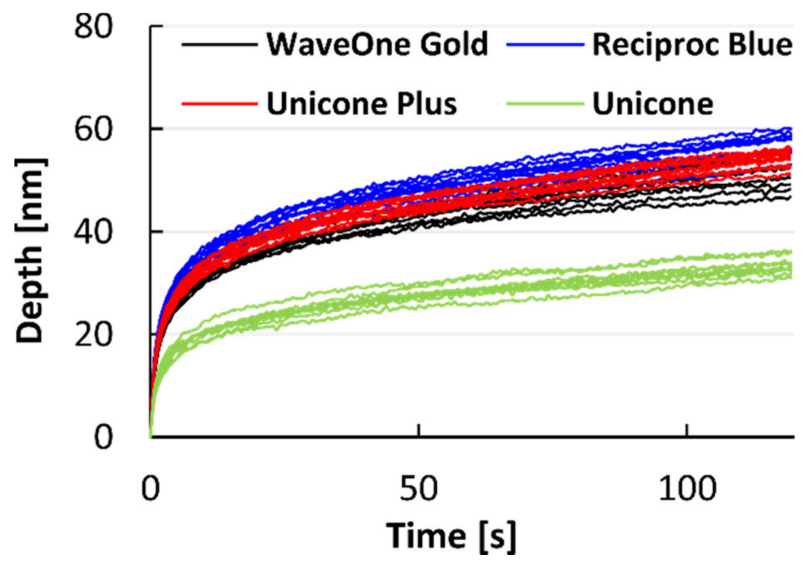

Figure 7. Normalized indentation creep curves.

\section{Discussion}

When considering cyclic fatigue test results, the experimental conditions must be carefully taken into account as they predetermine their practical significance. In this study, the fatigue tests were performed at the typical intracanal temperature of $35^{\circ} \mathrm{C}$, which approaches the temperature of the body. Furthermore, the reciprocating motion in the mode RECIPROC ALL $\left(150^{\circ}\right.$ counterclockwise and then $30^{\circ}$ clockwise rotation with a speed of $300 \mathrm{rpm}$ ) was used. In general, other operating modes can also be used such as WAVEONE ALL $\left(170^{\circ}\right.$ counter clockwise and then $50^{\circ}$ clockwise rotation with a 
speed of $350 \mathrm{rpm}$ ) [24]. Nevertheless, the literature data comparing cyclic fatigue using both reciprocating motions and converting time to fracture into number of cycles leading to fracture of the instrument $[21,24,40]$ does not show any differences in cyclic fatigue resistance [41].

It is well known that high importance should also be given to the trajectory of the instrument when introduced into the tooth/artificial canal, as this can significantly influence results [42]. Within this study, all instruments were tested in the same artificial canal and no statistically significant differences in the length of fractured fragments were observed. This can be considered as a proof of the correct positioning of instruments inside the artificial canal [14,43], and in turn also that all instruments were confronted by similar stresses, thereby ensuring sufficient reproducibility [44].

Comparison of the fatigue resistance (see Figure 2) clearly shows how peculiarities of different manufacturing processes significantly affect cyclic fatigue resistance $[18,19]$ and in general also mechanical and tribological properties. It is clear that the Unicone made of M-wire was significantly less resistant to cyclic fatigue in comparison to Reciproc Blue, WaveOne Gold and Unicon Plus, all made of CM-wire; this agrees with other studies comparing effect of phase composition on NiTi-based alloys [14,20-22]. Our study also shows that Reciproc Blue is more resistant to cyclic fatigue than WaveOne Gold, similar to previous studies $[16,20]$. The higher fatigue resistance of Reciproc Blue compared to WaveOne Gold is mainly attributed to different thermomechanical treatment. Reciproc Blue is ground before appropriate heat-cooling process, leading to the creation of a blue surface layer, while WaveOne Gold is ground after an additional slow heat-cooling process, leading to a gold surface layer made from $\mathrm{Ni}_{3} \mathrm{Ti}_{4}$ precipitate $[16,45]$. Smaller differences in the cyclic fatigue resistance of Reciproc Blue and Unicone Plus compared to Reciproc Blue to WaveOne Gold may be due to the fact that both Reciproc Blue and Unicone Plus are ground prior to their thermal treatments, unlike WaveOne Gold. In addition, the transformation temperatures and phase composition of the used NiTi alloys are important parameters. It is known that the durability of Reciproc Blue compared to WaveOne Gold is mainly attributed to different thermomechanical treatment, despite having a lower transformation temperature [46]. This is mainly explained by the presence of more stable martensite [13]. Being composed mainly of martensite, these instruments are able to resist cyclic fatigue due to its reorientation properties more than instruments based on austenite, in our case Unicone [13].

Another factor influencing cyclic fatigue resistance is cross-section area. Fatigue fracture originates at the maximum bending point of the instrument during root canal shaping. Tensile stress amplitude increases with larger instrument diameter. The higher the tensile strain amplitude on the surface is, the lower cyclic fatigue resistance will be [47,48]. In a study done by Di Nardo et al. [17], it was proven that a higher mass of alloy (i.e., a larger cross-section area) lowers cyclic fatigue resistance when using instruments from the same treated alloy with the same properties. However, in our study, the resistance of WaveOne Gold to cyclic fatigue was lower compared to Reciproc Blue and Unicone Plus, although its cross-sectional area is the smallest one. In the case of Unicone Plus and Reciproc Blue one can see that the latter, having a larger cross-sectional area, is more resistant to cyclic fatigue, though not statistically significantly. These results do not correlate with the last mentioned study [17]. Nevertheless, it should be stressed that other factors such as microstructure and phase composition have to be considered. In other words, the cross-sectional area is not the only parameter affecting or predetermining the performance of the NiTi endodontic instruments, as supported by comparison of Figures 2 and 3 for Unicone and Unicone Plus, for example. Although their cross-sectional areas are very similar, their performance differs significantly. Our results show that even small differences in manufacturing processes may have a great impact on the cyclic fatigue resistance of the instruments used in our study, in addition to cross-section area [16]. The cross-section shape is another plausible parameter, observable from the cross-sections in Figure 3, that correlates with our results. It is generally assumed that the S-shaped cross-section design, as in the case of Reciproc Blue, 
is more advantageous in terms of cyclic fatigue due to less blade engagement compared to instruments with a higher number of blades [49].

The process of cyclic fatigue fracture originates with the forming of nano and $\mathrm{mi}-$ crocracks, predominantly initiated on the surface. In most cases surface imperfections created during the machining or any other technological operation are involved at the very beginning of crack formation. Surface and near subsurface microcracks and other voids act as stress concentrators, initiating the fracture process during mechanical loading. Once the crack is formed, it grows with each subsequent loading cycle. The gradual process of structural damage proceeds and the instrument is progressively weakened. This process continuous until the crack reaches its critical size and the catastrophic fracture ultimately takes place. Unfortunately, this happens suddenly and unexpectedly, with negative effects on the quality and course of endodontic treatment [50,51]. Lopes et al. [15] proved that lower surface roughness leads to increased cyclic fatigue resistance. However, this does not corelate with our results, where Unicone Plus had the lowest roughness but does not exhibit the highest resistance in cyclic fatigue tests, and WaveOne Gold, with the highest roughness, does not exhibit the lowest resistance; see Figure 2 and Table 2. This could be due to a higher effect of the other factors discussed in relation to cyclic fatigue compared to the surface roughness.

Although high hardness is a suitable parameter against damage initiation due to the resistance to notching, it can be disadvantageous in fatigue tests. Materials of higher hardness are usually more brittle, which leads to rapid propagation and macroscopic cracking of the sample after the initial initiation of the microcrack [52-54]. This correlates well with the results of indentation tests, where Unicone has significantly higher hardness than other three samples, while also failing first during the fatigue test. The values of Elasticity modulus for all four samples are relatively similar. However, the increase between the $2 \mathrm{~mm}$ and $6.4 \mathrm{~mm}$ cross-sections is noticeable for each of the samples. This probably indicates slight differences in the structure and/or elemental/phase composition of the material in the apex area in comparison to the main body. According to the Hook's law, a higher modulus of elasticity imposes higher mechanical stresses for the same elastic deformation, which corelates well with the occurrence of the instrument rupture points (=distance from the apex) during fatigue tests.

In materials science, not only hardness and modulus values but also their ratios are very often used for description of the material response to external loading [55]. For example, in tribological practice, the $H / E$ (defined as the elastic strain to failure) or $H^{3} / E^{2}$ ratios (defined as resistance to plastic deformation) are often considered more relevant parameters for description of wear behavior than mere hardness. In addition, the $H / E$ ratio appears in many equations describing critical stress intensity, Kc, representing or indicating the indentation fracture toughness. Based on these equations, a material's resistance to crack formation and propagation is proportional to $(E / H)^{1 / 2}[56,57]$.

Another important material property with direct practical relevance is contact yield pressure, or in other words, resistance to plastic deformation, which scales with $H^{3} / E^{2}$ [58]. It is usually observed that critical load for non-elastic deformation grows with the value of $H^{3} / E^{2}$ and in turn postpones the fracture initiation during quasi-static indentation tests. On the other hand, damage tolerance was proved to scale reciprocally to $H^{3} / E^{2}$ (i.e., to $E^{2} / H^{3}$ ) during dynamic impact mechanical testing, as shown by Beake [59]. This clearly reflects the complexity of tribo/mechanical testing and emphasizes the peculiarities of different loading conditions (static, quasistatic, dynamic). This means that material elasticity, as well as ductility, plays an important role in a material's erosive, abrasive and impact wear, and must be considered when overall tribo-mechanical performance is evaluated.

Comparison of the performance of individual instruments through the probability of fracture vs. time to failure (Figure 2) and hardness to elastic modulus ratios (Figure 6) implies a relationship. The increased operation time, i.e., longer time to fracture, seems to scale with the decrease of $H / E$, which predicts higher fracture toughness, as can be seen from a comparison of Unicone and the other instruments (WaveOne Gold, Unicone Plus 
and Reciproc Blue). This study also shows that $H^{3} / E^{2}$ values are lowest for the Unicone Plus and Reciproc Blue, with the longest operation time, and highest for Unicone, with the shortest operation time; compare especially the values obtained at the distance of $6.4 \mathrm{~mm}$ from the apex of the instrument (Figure 5d). A possible explanation might be based on more effective mechanisms of energy dissipation and strain accommodation. However, it should also be notated that influences other than material-related parameters might be responsible for the best performance, such as the shape and design of the instrument, the cross-sectional area, and/or the surface roughness. A similar correlation between $H^{3} / E^{2}$ and the results of a dynamic fatigue test was also reported by Beake, who reported that resistance to crack propagation during repetitive impact increases with the decrease of $H^{3} / E^{2}$ in the case of optical coatings [59].

It should be noted that the multi-method approach used in this study follows current trends in endodontics research. Similar multi-method approaches combining cyclic fatigue, torsion resistance, flexibility and cutting efficiency were recently reported by Silva et al. [60]. It is believed that this approach is necessary for the further development of understanding of the mechanical strength and limits of endodontic instruments.

\section{Conclusions}

Within the limitations of this study, differences between endodontic instruments were observed in their overall geometric design, such as the number of edges/blades, cross section area, and surface roughness. It was shown that in terms of cyclic fatigue resistance Unicone Plus and Reciproc Blue outperformed WaveOne Gold, while the worst results were achieved by Unicone. The comparison of the cyclic fatigue resistance test and nanoindentation suggests a correlation between fatigue resistance and the hardness to elastic modulus ratios $H / E$ and $H^{3} / E^{2}$, as well as tendency to creep.

Author Contributions: Conceptualization, A.J. and R.Č.; Formal analysis, J.T., L.V. and P.H.; Funding acquisition, A.J. and R.Č.; Investigation, L.V., P.J., L'.H. and P.H.; Methodology, A.J.; Supervision, R.Č.; Visualization, J.T. and L.V.; Writing—original draft, A.J., J.T. and R.Č.; Writing—review \& editing, A.J., J.T., L.V. and R.Č. All authors contributed to the article and approved the submitted version. All authors have read and agreed to the published version of the manuscript.

Funding: The research was partially funded by the project No. CZ.02.1.01/0.0/0.0/17 049/0008422 of the Ministry of Education, Youth and Sports of the Czech Republic. R.Č., J.T. and L.V. also thank the project No. TN01000038 of the Technology Agency of the Czech Republic for support of their workplace. L.V. also acknowledges the project IGA_PrF_2021_004 of Palacky University.

Institutional Review Board Statement: Not applicable.

Informed Consent Statement: Not applicable.

Conflicts of Interest: The authors declare no conflict of interest.

\section{References}

1. Parashos, P.; Messer, H.H. Rotary NiTi Instrument Fracture and its Consequences. J. Endod. 2006, 32, 1031-1043. [CrossRef] [PubMed]

2. Sattapan, B.; Nervo, G.J.; Palamara, J.E.A.; Messer, H.H. Defects in Rotary Nickel-Titanium Files After Clinical Use. J. Endod. 2000, 26, 161-165. [CrossRef] [PubMed]

3. Peng, B.; Shen, Y.; Cheung, G.S.P.; Xia, T.J. Defects in ProTaper S1 instruments after clinical use: Longitudinal examination. Int. Endod. J. 2005, 38, 550-557. [CrossRef]

4. Shen, Y.; Cheung, G.S.-P.; Peng, B.; Haapasalo, M. Defects in Nickel-Titanium Instruments after Clinical Use. Part 2: Fractographic Analysis of Fractured Surface in a Cohort Study. J. Endod. 2009, 35, 133-136. [CrossRef] [PubMed]

5. Parashos, P.; Gordon, I.; Messer, H.H. Factors Influencing Defects of Rotary Nickel-Titanium Endodontic Instruments After Clinical Use. J. Endod. 2004, 30, 722-725. [CrossRef]

6. Cheung, G.S.P.; Darvell, B.W. Fatigue testing of a NiTi rotary instrument. Part 2: Fractographic analysis. Int. Endod. J. 2007, 40, 619-625. [CrossRef]

7. Alapati, S.B.; Brantley, W.A.; Svec, T.A.; Powers, J.M.; Nusstein, J.M.; Daehn, G.S. SEM Observations of Nickel-Titanium Rotary Endodontic Instruments that Fractured During Clinical Use. J. Endod. 2005, 31, 40-43. [CrossRef]

8. Thompson, S.A. An overview of nickel-titanium alloys used in dentistry. Int. Endod. J. 2000, 33, 297-310. [CrossRef] 
9. Zhou, H.; Peng, B.; Zheng, Y.-F. An overview of the mechanical properties of nickel-titanium endodontic instruments. Endod. Top. 2013, 29, 42-54. [CrossRef]

10. Miyazaki, S.; Otsuka, K. Deformation and transition behavior associated with theR-phase in Ti-Ni alloys. Metall. Trans. A 1986, 17, 53-63. [CrossRef]

11. Larsen, C.M.; Watanabe, I.; Glickman, G.N.; He, J. Cyclic Fatigue Analysis of a New Generation of Nickel Titanium Rotary Instruments. J. Endod. 2009, 35, 401-403. [CrossRef]

12. Kuhn, G.; Jordan, L. Fatigue and Mechanical Properties of Nickel-Titanium Endodontic Instruments. J. Endod. 2002, 28, 716-720. [CrossRef]

13. Zupanc, J.; Vahdat-Pajouh, N.; Schäfer, E. New thermomechanically treated NiTi alloys-A review. Int. Endod. J. 2018, 51, 1088-1103. [CrossRef] [PubMed]

14. Plotino, G.; Grande, N.M.; Testarelli, L.; Gambarini, G.; Castagnola, R.; Rossetti, A.; Özyürek, T.; Cordaro, M.; Fortunato, L. Cyclic Fatigue of Reciproc and Reciproc Blue Nickel-titanium Reciprocating Files at Different Environmental Temperatures. J. Endod. 2018, 44, 1549-1552. [CrossRef] [PubMed]

15. Lopes, H.P.; Elias, C.N.; Vieira, M.V.B.; Vieira, V.T.L.; de Souza, L.C.; dos Santos, A.L. Influence of Surface Roughness on the Fatigue Life of Nickel-Titanium Rotary Endodontic Instruments. J. Endod. 2016, 42, 965-968. [CrossRef] [PubMed]

16. Oh, S.; Kum, K.-Y.; Kim, H.-J.; Moon, S.-Y.; Kim, H.-C.; Chaniotis, A.; Perinpanayagam, H.; Pedullá, E.; Chang, S.W. Bending resistance and cyclic fatigue resistance of WaveOne Gold, Reciproc Blue, and HyFlex EDM instruments. J. Dent. Sci. 2020, 15, 472-478. [CrossRef] [PubMed]

17. Di Nardo, D.; Gambarini, G.; Seracchiani, M.; Mazzoni, A.; Zanza, A.; Giudice, A.; Angelo, M.; Testarelli, L. Influence of different cross-section on cyclic fatigue resistance of two nickel-titanium rotary instruments with same heat treatment: An in vitro study. Saudi Endod. J. 2020, 10, 221.

18. Zinelis, S.; Darabara, M.; Takase, T.; Ogane, K.; Papadimitriou, G.D. The effect of thermal treatment on the resistance of nickel-titanium rotary files in cyclic fatigue. Oral Surg. Oral Med. Oral Pathol. Oral Radiol. Endod. 2007, 103, 843-847. [CrossRef]

19. Zinelis, S.; Eliades, T.; Eliades, G. A metallurgical characterization of ten endodontic Ni-Ti instruments: Assessing the clinical relevance of shape memory and superelastic properties of Ni-Ti endodontic instruments. Int. Endod. J. 2010, 43, 125-134. [CrossRef]

20. Keskin, C.; Inan, U.; Demiral, M.; Keleş, A. Cyclic Fatigue Resistance of Reciproc Blue, Reciproc, and WaveOne Gold Reciprocating Instruments. J. Endod. 2017, 43, 1360-1363. [CrossRef]

21. Özyürek, T. Cyclic Fatigue Resistance of Reciproc, WaveOne, and WaveOne Gold Nickel-Titanium Instruments. J. Endod. 2016, 42, 1536-1539. [CrossRef]

22. Gao, Y.; Gutmann, J.L.; Wilkinson, K.; Maxwell, R.; Ammon, D. Evaluation of the Impact of Raw Materials on the Fatigue and Mechanical Properties of ProFile Vortex Rotary Instruments. J. Endod. 2012, 38, 398-401. [CrossRef]

23. Keleş, A.; Eymirli, A.; Uyanık, O.; Nagas, E. Influence of static and dynamic cyclic fatigue tests on the lifespan of four reciprocating systems at different temperatures. Int. Endod. J. 2019, 52, 880-886. [CrossRef] [PubMed]

24. Kim, H.-C.; Kwak, S.-W.; Cheung, G.S.-P.; Ko, D.-H.; Chung, S.-M.; Lee, W. Cyclic Fatigue and Torsional Resistance of Two New Nickel-Titanium Instruments Used in Reciprocation Motion: Reciproc Versus WaveOne. J. Endod. 2012, 38, 541-544. [CrossRef] [PubMed]

25. Plotino, G.; Grande, N.M.; Melo, M.C.; Bahia, M.G.; Testarelli, L.; Gambarini, G. Cyclic fatigue of NiTi rotary instruments in a simulated apical abrupt curvature. Int. Endod. J. 2010, 43, 226-230. [CrossRef] [PubMed]

26. Plotino, G.; Testarelli, L.; Al-Sudani, D.; Pongione, G.; Grande, N.M.; Gambarini, G. Fatigue resistance of rotary instruments manufactured using different nickel-titanium alloys: A comparative study. Odontology 2014, 102, 31-35. [CrossRef]

27. Plotino, G.; Grande, N.M.; Testarelli, L.; Gambarini, G. Cyclic fatigue of Reciproc and WaveOne reciprocating instruments. Int. Endod. J. 2012, 45, 614-618. [CrossRef] [PubMed]

28. Grande, N.M.; Plotino, G.; Pecci, R.; Bedini, R.; Malagnino, V.A.; Somma, F. Cyclic fatigue resistance and three-dimensional analysis of instruments from two nickel-titanium rotary systems. Int. Endod. J. 2006, 39, 755-763. [CrossRef]

29. De Hemptinne, F.; Slaus, G.; Vandendael, M.; Jacquet, W.; De Moor, R.J.; Bottenberg, P. In Vivo Intracanal Temperature Evolution during Endodontic Treatment after the Injection of Room Temperature or Preheated Sodium Hypochlorite. J. Endod. 2015, 41, 1112-1115. [CrossRef]

30. Huang, X.; Shen, Y.; Wei, X.; Haapasalo, M. Fatigue Resistance of Nickel-titanium Instruments Exposed to High-concentration Hypochlorite. J. Endod. 2017, 43, 1847-1851. [CrossRef]

31. De Vasconcelos, R.A.; Murphy, S.; Carvalho, C.A.T.; Govindjee, R.G.; Govindjee, S.; Peters, O.A. Evidence for Reduced Fatigue Resistance of Contemporary Rotary Instruments Exposed to Body Temperature. J. Endod. 2016, 42, 782-787. [CrossRef]

32. Grande, N.M.; Plotino, G.; Silla, E.; Pedullà, E.; DeDeus, G.; Gambarini, G.; Somma, F. Environmental Temperature Drastically Affects Flexural Fatigue Resistance of Nickel-titanium Rotary Files. J. Endod. 2017, 43, 1157-1160. [CrossRef]

33. Pedullà, E.; Lo Savio, F.; Boninelli, S.; Plotino, G.; Grande, N.M.; La Rosa, G.; Rapisarda, E. Torsional and Cyclic Fatigue Resistance of a New Nickel-Titanium Instrument Manufactured by Electrical Discharge Machining. J. Endod. 2016, 42, 156-159. [CrossRef] [PubMed]

34. Plotino, G.; Grande, N.M.; Cotti, E.; Testarelli, L.; Gambarini, G. Blue Treatment Enhances Cyclic Fatigue Resistance of Vortex Nickel-Titanium Rotary Files. J. Endod. 2014, 40, 1451-1453. [CrossRef] 
35. Plotino, G.; Grande, N.M.; Mercadé Bellido, M.; Testarelli, L.; Gambarini, G. Influence of Temperature on Cyclic Fatigue Resistance of ProTaper Gold and ProTaper Universal Rotary Files. J. Endod. 2017, 43, 200-202. [CrossRef] [PubMed]

36. Hülsmann, M. Research that matters: Studies on fatigue of rotary and reciprocating NiTi root canal instruments. Int. Endod. J. 2019, 52, 1401-1402. [CrossRef]

37. Aoun, C.; Nehme, W.; Naaman, A.; Khalil, I. Review and classification of endodontic heat treatment procedures. Int. J. Curr. Res. 2017, 9, 51300-51306.

38. Oliver, W.C.; Pharr, G.M. Measurement of hardness and elastic modulus by instrumented indentation: Advances in understanding and refinements to methodology. J. Mater. Res. 2004, 19, 3-20. [CrossRef]

39. Standardization, I.O.F. Geometrical Product Specifications (GPS)—Surface texture: Profile method-Terms, definitions and surface texture parameters. In 01.040.17 Metrology and Measurement. Physical Phenomena (Vocabularies) 17.040.20 Properties of Surfaces; ISO 4287; ISO_International Organization for Standardization: Geneve, Switzerland, 1997; p. 25.

40. Özyürek, T.; Gündoğar, M.; Yılmaz, K.; Uslu, G. Bending resistance and cyclic fatigue life of Reciproc Blue, WaveOne Gold, and Genius files in a double (S-shaped) curved canal. J. Dent. Res. Dent. Clin. Dent. Prospect. 2017, 11, 241-246. [CrossRef]

41. Pedullà, E.; Grande, N.M.; Plotino, G.; Gambarini, G.; Rapisarda, E. Influence of continuous or reciprocating motion on cyclic fatigue resistance of 4 different nickel-titanium rotary instruments. J. Endod. 2013, 39, 258-261. [CrossRef]

42. Plotino, G.; Grande, N.M.; Mazza, C.; Petrovic, R.; Testarelli, L.; Gambarini, G. Influence of size and taper of artificial canals on the trajectory of NiTi rotary instruments in cyclic fatigue studies. Oral Surg. Oral Med. Oral Pathol. Oral Radiol. Endod. 2010, 109, e60-e66. [CrossRef]

43. Plotino, G.; Costanzo, A.; Grande, N.M.; Petrovic, R.; Testarelli, L.; Gambarini, G. Experimental Evaluation on the Influence of Autoclave Sterilization on the Cyclic Fatigue of New Nickel-Titanium Rotary Instruments. J. Endod. 2012, 38, 222-225. [CrossRef] [PubMed]

44. Plotino, G.; Grande, N.M.; Cordaro, M.; Testarelli, L.; Gambarini, G. A Review of Cyclic Fatigue Testing of Nickel-Titanium Rotary Instruments. J. Endod. 2009, 35, 1469-1476. [CrossRef]

45. Pereira, É.S.J.; Viana, A.C.D.; Buono, V.T.L.; Peters, O.A.; Azevedo Bahia, M.G.d. Behavior of Nickel-Titanium Instruments Manufactured with Different Thermal Treatments. J. Endod. 2015, 41, 67-71. [CrossRef]

46. Martins, J.N.R.; Silva, E.J.N.L.; Marques, D.; Belladonna, F.; Simões-Carvalho, M.; Vieira, V.T.L.; Antunes, H.S.; Braz Fernandes, F.M.B.; Versiani, M.A. Design, metallurgical features, mechanical performance and canal preparation of six reciprocating instruments. Int. Endod. J. 2021, 54, 1623-1637. [CrossRef] [PubMed]

47. Bahia, M.G.A.; Buono, V.T.L. Decrease in the fatigue resistance of nickel-titanium rotary instruments after clinical use in curved root canals. Oral Surg. Oral Med. Oral Pathol. Oral Radiol. Endod. 2005, 100, 249-255. [CrossRef] [PubMed]

48. Ninan, E.; Berzins, D.W. Torsion and Bending Properties of Shape Memory and Superelastic Nickel-Titanium Rotary Instruments. J. Endod. 2013, 39, 101-104. [CrossRef] [PubMed]

49. Ha, J.H.; Cheung, G.S.P.; Versluis, A.; Lee, C.J.; Kwak, S.W.; Kim, H.C. 'Screw-in' tendency of rotary nickel-titanium files due to design geometry. Int. Endod. J. 2015, 48, 666-672. [CrossRef]

50. Callister, W.D. Materials Science and Engineering, 8th ed.; John Wiley and Sons Ltd.: Chichester, UK, $2010 ;$ p. 1000.

51. Getsov, L.B.; Rybinkov, A.I.; Malashenko, I.S. Cyclic strength of high-temperature alloys with coatings. Strength Mater. 1988, 20, 1576-1581. [CrossRef]

52. Casagrande, A.; Cammarota, G.P.; Micele, L. Relationship between fatigue limit and Vickers hardness in steels. Mater. Sci. Eng. A 2011, 528, 3468-3473. [CrossRef]

53. Wang, R.-J.; Shang, D.-G. Low-cycle fatigue life prediction of spot welds based on hardness distribution and finite element analysis. Int. J. Fatigue 2009, 31, 508-514. [CrossRef]

54. Keryvin, V.; Hoang, V.H.; Shen, J. Hardness, toughness, brittleness and cracking systems in an iron-based bulk metallic glass by indentation. Intermetallics 2009, 17, 211-217. [CrossRef]

55. Leyland, A.; Matthews, A. On the significance of the H/E ratio in wear control: A nanocomposite coating approach to optimised tribological behaviour. Wear 2000, 246, 1-11. [CrossRef]

56. Pintaude, G. Introduction of the Ratio of the Hardness to the Reduced Elastic Modulus for Abrasion. In Tribology -Fundamentals and Advancements; Gegner, J., Ed.; IntechOpen: Rijeka, Croatia, 2013.

57. Ni, W.; Cheng, Y.-T.; Lukitsch, M.J.; Weiner, A.M.; Lev, L.C.; Grummon, D.S. Effects of the ratio of hardness to Young's modulus on the friction and wear behavior of bilayer coatings. Appl. Phys. Lett. 2004, 85, 4028-4030. [CrossRef]

58. Tsui, T.Y.; Pharr, G.M.; Oliver, W.C.; Chung, Y.W.; Cutiongco, E.C.; Bhatia, C.S.; White, R.L.; Rhoades, R.L.; Gorbatkins, S.M. Nanoindentation and nanoscratching of hard coating materials for magnetic disks. MSEng 1995, 356, 767-772.

59. Beake, B.D.; Isern, L.; Bhattacharyya, D.; Endrino, J.L.; Lawson, K.; Walker, T. Nano- and micro-scale impact testing of zirconia, alumina and zirconia-alumina duplex optical coatings on glass. Wear 2020, 462, 203499. [CrossRef]

60. Silva, E.J.N.L.; Martins, J.N.R.; Lima, C.O.; Vieira, V.T.L.; Braz Fernandes, F.M.; De-Deus, G.; Versiani, M.A. Mechanical Tests, Metallurgical Characterization, and Shaping Ability of Nickel-Titanium Rotary Instruments: A Multimethod Research. J. Endod. 2020, 46, 1485-1494. [CrossRef] [PubMed] 